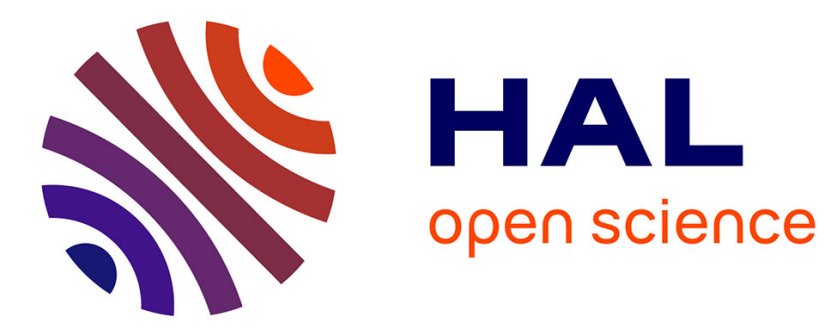

\title{
Dispersant use as a response to oil spills: toxicological effects on fish cardiac performance
}

Thomas Milinkovitch, Hélène Thomas-Guyon, Christel Lefrançois, Nathalie

Imbert

\section{- To cite this version:}

Thomas Milinkovitch, Hélène Thomas-Guyon, Christel Lefrançois, Nathalie Imbert. Dispersant use as a response to oil spills: toxicological effects on fish cardiac performance. Fish Physiology and Biochemistry, 2013, pp.6. 10.1007/s10695-012-9696-z . hal-01178080

\section{HAL Id: hal-01178080 \\ https://hal.science/hal-01178080}

Submitted on 17 Jul 2015

HAL is a multi-disciplinary open access archive for the deposit and dissemination of scientific research documents, whether they are published or not. The documents may come from teaching and research institutions in France or abroad, or from public or private research centers.
L'archive ouverte pluridisciplinaire HAL, est destinée au dépôt et à la diffusion de documents scientifiques de niveau recherche, publiés ou non, émanant des établissements d'enseignement et de recherche français ou étrangers, des laboratoires publics ou privés. 


\section{Dispersant use as a response to oil spills: toxicological effects on fish cardiac performance}

Thomas Milinkovitch ${ }^{1 *}$, Hélène Thomas-Guyon ${ }^{1}$, Christel Lefrançois ${ }^{1}$, Nathalie Imbert ${ }^{1}$

\section{Affiliations}

${ }^{1}$ Littoral Environnement et Sociétés (LIENSs), UMR 7266, CNRS-Université de La Rochelle, 2 rue Olympe de Gouges - F-17042 La Rochelle Cedex 01, France.

Email: thomas.milinkovitch01@univ-lr.fr ; helene.thomas@univ-lr.fr ; nathalie.imbert@univlr.fr ; christel.lefrancois@univ-lr.fr

* Corresponding author: T. Milinkovitch

Littoral Environnement et Sociétés (LIENSs)

UMR 6250, CNRS-Université de La Rochelle

2 rue Olympe de Gouges

F-17042 La Rochelle Cedex 01, France

Email : thomas.milinkovitch01@univ-lr.fr

tel : $+33(0) 546507648$

fax : +33(0)5 46458264 


\begin{abstract}
Dispersant use is a controversial technique used to respond to oil spills in nearshore areas. In order to assess the toxicity of this technique, this study evaluated the cardiac toxicological effects on juvenile golden grey mullets Liza aurata exposed for $48 \mathrm{~h}$ to either dispersant alone, chemically dispersed oil, mechanically dispersed oil, the water soluble fraction of oil or to a control condition. Following exposure, the positive inotropic effects of adrenaline were assessed in order to evaluate a potential impairment on the cardiac performance. The results revealed an impairment of the positive inotropic effects of adrenaline for all the contaminants (single dispersant, dispersed and undispersed oil, water soluble fraction of oil). This suggests that: (i) cardiac performance is a valuable parameter to study the physiopathological effects of dispersed oil; (ii) dispersant application is likely to impair cardiac performance.
\end{abstract}

Keywords: dispersant, cardiac performance, force of contraction, contraction velocity, heart, Liza aurata. 


\section{Introduction}

Dispersant use is a response to oil spills since this method enhances hydrocarbon bacterial degradation (Thiem, 1994; Churchill et al., 1995) and reduces the risk of contamination for surface-occupying organisms (e.g. seabirds and marine mammals). However, using dispersant on an oil slick induces the formation of oil-surfactant droplets in the water column and consequently leads to an extreme ecotoxicological event for aquatic organisms with a concentration of total petroleum hydrocarbons (TPHs) in the water column reaching $50 \mathrm{mg} / \mathrm{L}$ (Lewis and Daling, 2001). The intensity of this contamination is more important in nearshore areas since shallow waters mean a low dissemination potential. For this purpose, the present study investigated the toxicity of dispersed oil upon a species living in nearshore areas, the golden grey mullet, Liza aurata.

A recent study conducted by Claireaux and Davoodi (2010) showed an impact of petroleum hydrocarbons upon the cardiac output and the heart rate in Solea solea when metabolic demand increases. The authors suggested that this impaired ability of the heart to respond to increased metabolic demand could be due to an altered adrenergic response. On this basis, the present paper investigates the impact of dispersed oil on the adrenergic response of the myocardium of juvenile Liza aurata. The impairment of adrenergic response was evaluated by measuring the alteration of the positive inotropic effect following an increase of circulating adrenaline. Through an in vitro study conducted on isolated ventricles, two parameters involved in the inotropic effects (according to the definition of Klabunde, 2011) were assessed: the force of contraction and the contraction velocity. 


\section{Materials and methods}

Prior to exposure, 70 juveniles of Liza aurata $(37.73 \pm 0.53 \mathrm{~g}$; mean \pm standard error of the mean) were acclimatised for at least three weeks in 300-L flow-through tanks with the following physico-chemical parameters: dissolved oxygen $99 \pm 2 \%$ air saturation; salinity 35 $\pm 1 \%$; and temperature $14.5 \pm 0.1^{\circ} \mathrm{C}$ (mean \pm standard error of the mean). After this period, fish were exposed for $48 \mathrm{~h}$ to five different treatments: (i) chemically dispersed oil (CD) simulating dispersant application, made by homogenising $20 \mathrm{~g}$ brut Arabian light petroleum and $1 \mathrm{~g}$ dispersant in $300 \mathrm{~L}$ sea water; (ii) dispersant alone (D) in sea water as an internal control of chemically dispersed oil, made by homogenising $1 \mathrm{~g}$ dispersant in $300 \mathrm{~L}$ sea water; (iii) mechanically dispersed oil (MD) simulating natural dispersion, made by homogenising $20 \mathrm{~g}$ petroleum in $300 \mathrm{~L}$ sea water; (iv) the water-soluble fraction of oil (WSF), simulating an oil slick confinement response technique, made by pouring a $20 \mathrm{~g}$ confined oil slick on the surface of $300 \mathrm{~L}$ sea water; and (v) $300 \mathrm{~L}$ sea water alone (C : control condition). Fish of this study were exposed in the same tanks (static water systems) as the fish used in another study (Milinkovitch et al., 2012) in which the exposure protocol is described in detail. Total petroleum hydrocarbons (TPHs) and concentrations of the sum of the 16 polycyclic aromatic hydrocarbons (PAHs; listed by the USEPA as priority pollutants) are summarised in Table 1. TPH concentrations of exposure are consistent with the concentration values observed in situ during oil spills (as previously discussed in Milinkovitch et al., 2012) since Cormack (1977) measured concentrations of $18 \mathrm{mg} / \mathrm{L}$ in the top $30 \mathrm{~cm}$ of the water column after chemical dispersion and Spooner (1970) measured $50 \mathrm{mg} / \mathrm{L}$ naturally dispersed oil after an oil spill in Tarut Bay (Saudi Arabia).

Following exposure, fish were euthanised using $2 \mathrm{ml}$ of eugenol (99\%, Sigma Aldricht chemicals, France) in $5 \mathrm{ml}$ seawater. The gallbladders were removed in order to evaluate PAH-derived metabolites to estimate PAH incorporation. Four $\mu \mathrm{L}$ of bile extracted from the 
gallbladders of fish were diluted in $996 \mu \mathrm{L}$ absolute ethanol (VWR International) in quartz cuvettes. Fixed wavelength fluorescence (FF) was then measured on a spectrofluorimeter (SAFAS Flx-Xenius, Monaco). Excitation-emission wavelength pairs 341:383 and 380:430 were employed to detect pyrene-derived and benzo[ $[a]$ pyrene-derived metabolites, respectively (Aas et al., 2000).

In parallel, the positive inotropic effect of increased adrenaline was assessed using an in vitro experiment adapted from Shiels and Farell (1997). Ventricles of each heart were removed and divided (from the apex to the base) in two strips. In a water-jacket bath containing $15{ }^{\circ} \mathrm{C}$ oxygenated physiological saline solution ( $\mathrm{NaCl} 124.1$ mmol. ${ }^{-1} ; \mathrm{KCl} 3.1 \mathrm{mmol}^{-1}{ }^{-1} \mathrm{CaCl}_{2} 2.5$

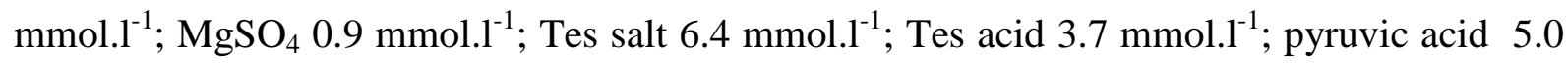
mmol. $\mathrm{l}^{-1}$; glucose $5.7 \mathrm{mmol} . \mathrm{l}^{-1}$ ), the base was attached to a fixed post and the apex to a filament connected to an isometric force transducer (ADInstrument, MLT0201/184). Each half-ventricle was then stimulated $(10 \mathrm{~V}, 10 \mathrm{~ms}$ duration) at each frequency including the physiological range $(0.2,0.5,0.8,1$ and $1.2 \mathrm{~Hz}$ ). Adrenergic response (positive inotropic effects) due to an increase of adrenaline was tested using a low $\left(\mathrm{AD}_{1}: 10 \mathrm{nM}\right.$; Shiels and Farell, 1997) and a high ( $\mathrm{AD}_{2}: 10 \mu \mathrm{M}$; Shiels and Farell, 1997) concentration of adrenaline. Force of contraction $(\mathrm{Fc})$ and contraction velocity $(+\mathrm{dF} / \mathrm{dt})$ were measured and expressed respectively in $\mathrm{mN} \cdot \mathrm{mm}^{-2}$ and $\mathrm{mN} \cdot \mathrm{mm}^{-2} \cdot \mathrm{s}^{-1}$. Data were statistically analysed using Statistica 8.0 (Statsoft, Inc) to conduct repeated measures ANOVA followed by planned comparison tests. ANOVA were conducted with adrenaline concentrations as the factor and frequencies as repeated measures for each treatment. This allows the difference due to adrenaline concentrations (between-adrenaline-concentration analyses), for each treatment, to be shown. ANOVA were conducted with treatment as the factor and frequencies as repeated measures, for each adrenaline concentration. This allows the difference due to treatment (betweentreatment analyses), for each adrenaline concentration, to be shown. 


\section{Results and discussion}
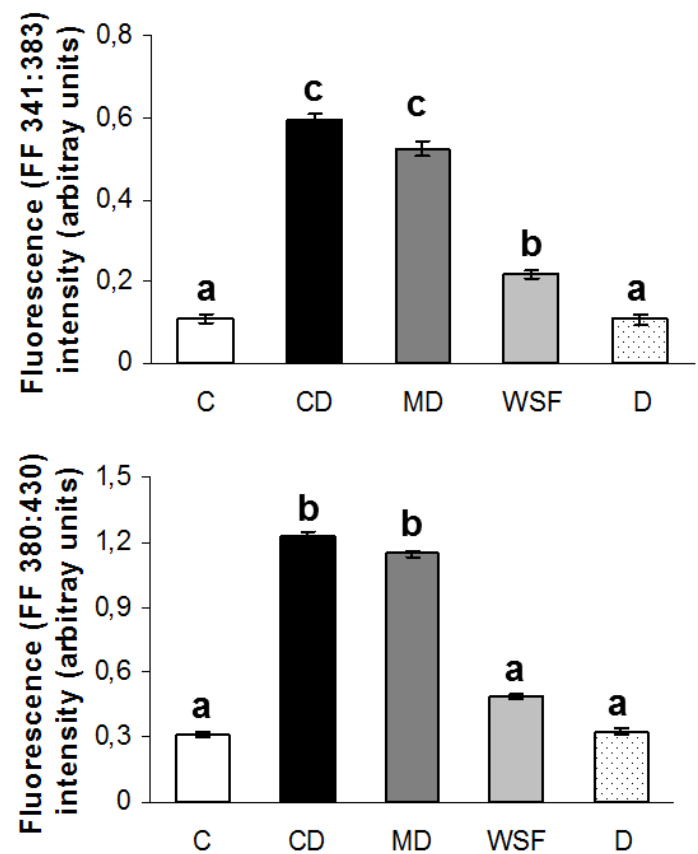

Fig. 1: Relative concentration of biliary PAH metabolites measured by fixed wavelength fluorescence (FF) levels after $48 \mathrm{~h}$ exposure to Control solution (C), Chemically Dispersed oil solution (CD), Mechanically Dispersed oil solution (MD), Water Soluble Fraction (WSF) solution and Dispersant solution (D) : (a) FF 343:383 (pyrene derived type of metabolites); (b) FF 380:430 (benzo[a]pyrene type of metabolites). Levels are expressed as fluorescence intensity. Values represent mean \pm standard error $(n=14$ per treatment). Different letters above bars indicate a significant difference $(\mathrm{P}<0.05)$. 

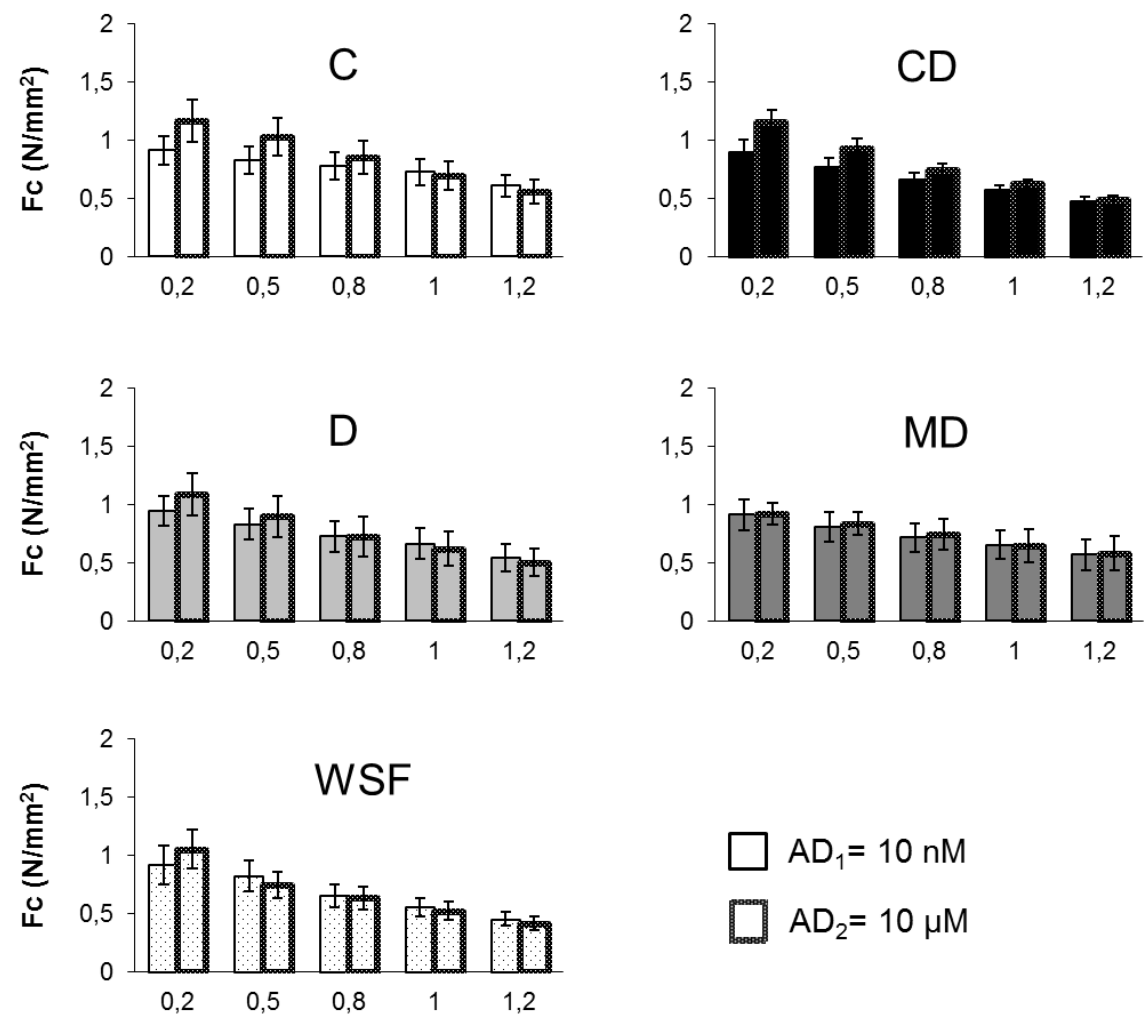

Fig. 2: Force of contraction ( $\mathrm{Fc}$ expressed in N.mm ${ }^{-2}$ ) of ventricular strips exposed to different concentration of adrenaline $\left(\mathrm{AD}_{1}: 10 \mathrm{nM}\right.$ and $\left.\mathrm{AD}_{2}: 10 \mu \mathrm{M}\right)$ at several frequencies $(0.2,0.5$, $0.8,1$ and $1.2 \mathrm{~Hz}$ ). Each histogram represents the mean ( \pm standard error mean) of the values $(\mathrm{N}=14)$ per treatment $(\mathrm{C}$ : control ; $\mathrm{CD}$ : chemical dispersion ; $\mathrm{D}$ : dispersant ; $\mathrm{MD}$ :

mechanical dispersion; WSF : water soluble fraction of oil) . 

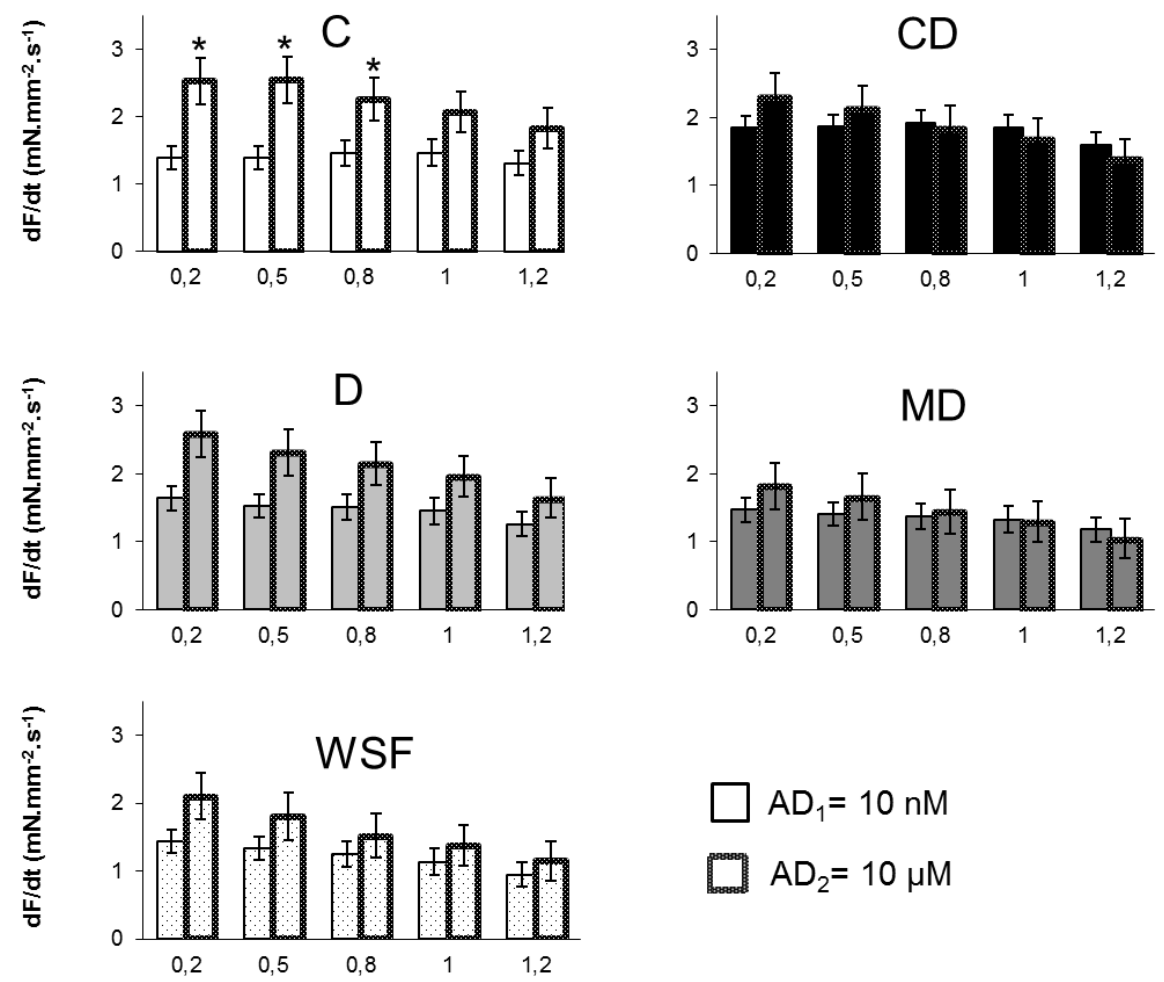

Fig. 3: Velocity of contraction (dF/dt expressed in N.mm $\left.{ }^{-2} \cdot \mathrm{s}^{-1}\right)$ of ventricular strips exposed to different concentration of adrenaline $\left(\mathrm{AD}_{1}: 10 \mathrm{nM}\right.$ and $\left.\mathrm{AD}_{2}: 10 \mu \mathrm{M}\right)$ at several frequencies $(0.2,0.5,0.8,1$ and $1.2 \mathrm{~Hz})$. Each histogram represents the mean ( \pm standard error mean) of the values $(\mathrm{N}=14)$ per treatment $(\mathrm{C}$ : control ; $\mathrm{CD}$ : chemical dispersion ; $\mathrm{D}:$ dispersant ; $\mathrm{MD}$ : mechanical dispersion; WSF : water soluble fraction of oil) .* indicates significant difference $(p<0.05)$ between the values obtained under $\mathrm{AD}_{1}$ and $\mathrm{AD}_{2}$ concentrations (intra frequency comparison).

Statistical analyses revealed an increase of PAH-derived metabolites in the gallbladders (figure 1) when fish were exposed to oil (i.e. when exposed to WSF, CD or MD) compared to control. However, following WSF exposure, the increase was less significant for pyrenederived metabolites and not observed for benzo[a]pyrene-derived metabolites. Taken together, these results are in accordance with the concentrations of the sum of PAHs initially assessed in the water column (Table 1, $\mathrm{T}=0 \mathrm{~h}$ ). Moreover, these results suggest that exposure to oil (WSF, MD, CD) could induce an increase in PAH incorporation; this incorporation being enhanced by dispersion (CD and MD). This last statement is in accordance with 
previous studies confirming an additive effect of the dispersion (whether mechanically or chemically) on the bioaccumulation of PAHs in teleosts fish (Camus et al., 1998; Ramachandran et al., 2004; Jung et al., 2009; Milinkovitch et al., 2011).

With respect to the cardiac performance (figures $\mathbf{2}$ and 3), whatever experimental conditions (including control), statistical analyses did not show that force of contraction (figure 2) was significantly increased under high adrenaline stimulation (between-adrenaline concentration analyses: $\mathrm{AD}_{2}$ compared to $\left.\mathrm{AD}_{1}\right)$. However, contraction velocity was significantly increased (figure 3) under high adrenaline level. Indeed, for control fish, our results showed a significant increase of contraction velocity due to the $\mathrm{AD}_{2}$ treatment (at the frequencies 0.20.5-0.8 Hz). This result indicates, for control fish, a cardiac adrenergic response, i.e. a positive inotropic effect, due to the increase in adrenaline. This was not observed for the other exposures (WSF, CD, MD, D) and suggests, consequently, that the cardiac adrenergic response was altered due to contamination. These results are in accordance with those of Incardona et al. (2004) who showed cardiac function defects in fish embryos exposed to PAHs, and with a recent study conducted by Thomasz et al. (2009) who showed, in Oreochromis niloticus, an impairment of cardiac performances due to another organic contaminant, trichlorfon. In spite of the fact that contaminants are likely to alter cardiac performance, the decrease of cardiac adrenergic response has also been observed in fish exposed to hypoxia (Petersen and Gamperl, 2009) suggesting that, in this study, contaminants could have acted indirectly through the modulation of this general stressor. For instance, impacts upon gill morphology and function, as described by Goanvec et al. (2010) in turbot exposed to oil, could have induced hypoxaemia leading to the observed decrease of cardiac adrenergic response.

Between-treatment analyses did not reveal any statistical differences due to contamination. For both AD1 and AD2, no significant difference due to treatment was found. Regarding on 
AD2 concentration of adrenaline this result means that, under high level of adrenaline, contraction velocity between control and the other treatments was not significantly altered.

Taken together, these results showed that contamination induced a reduction of the adrenergic response (between-adrenaline analyses). However, this reduction due to contamination is probably not sufficiently pronounced to induce a significant decrease of the contraction velocity under high levels of adrenaline (AD2). Extrapolated to the whole organism, this result means that contaminated fish exposed to additional stressors (such as predation, temperature, salinity) may not be able to increase metabolic rate accordingly. Thus, it could be suggested that contaminants tested in this study are likely to impair the survival of the fish. However, the fact that contraction velocity, under high levels of adrenaline, was not decreased significantly incites us to be cautious in our conclusions. On this basis, it would have been interesting to propose further investigations to be performed on additional cardiac parameters such as kinematics ones (e.g. time to peak tension, time to half relaxation). Although adrenergic response was altered due to contamination, no significant difference between the contaminants was observed in this study and consequently no difference in toxicity could be seen between dispersed oil (CD and/or MD) and undispersed oil (WSF) suggesting - on the basis of this single result - no additive effect of dispersant. Even so, in order to establish a framework of dispersant use in the nearshore area, further ecotoxicological studies (e.g. on several organisms and/or at several levels of biological organisation) should be conducted.

\section{References}

Aas E, Baussant T, Balk L, Liewenborg B, Andersen OK (2000) PAH metabolites in bile, cytochrome P4501A and DNA adducts as environmental risk parameters for chronic oil exposure: a laboratory experiment with Atlantic cod. Aquat Toxicol 51:241-258

Camus L, Aas E, Børseth JF (1998) Ethoxyresorufin-O-deethylase activity and fixed wavelength fluorescence detection of PAH metabolites in bile in Turbot (Scophthalmus 
maximus L.) exposed to a dispersed topped crude oil in a Continuous Flow System. Mar Environ Res 46:29-32

Churchill PF, Dudley RJ, Churchill SA (1995) Surfactant-enhanced bioremediation. Waste Management 15:371-377

Claireaux G and Davoodi F (2010) Effect of exposure to petroleum hydrocarbons upon cardio-respiratory function in the Common sole (Solea solea). Aquat Toxicol 98:113-119

Cormack D (1977) Oil pollution. Chemistry and Industry 14:605-608

Goanvec C, Poirier E, Le Floch S, Théron M (2011) Branchial structure and hydromineral equilibrium in juvenile turbot (Scophthalmus maximus) exposed to heavy fuel oil. Fish Physiol Biochem 37:363-371

Incardona JP, Collier TK, Scholz NL (2004) Defects in cardiac function precede morphological abnormalities in fish embryos exposed to polycyclic aromatic hydrocarbons. Toxicol Appl Pharmacol 196:191-205

Jung JH, Yim UH, Han GM, Shim WJ (2009) Biochemical changes in rockfish, Sebastes schlegeli, exposed to dispersed crude oil. Comparative Biochem Physiol Part C: Toxicol Pharmacol 150:218-223.

Klabunde RE (2011) Cardiovascular Physiology Concepts, second edition Lippincott Williams \& Wilkins, New York

Lewis A and Dailing P (2001) Oil spill dispersants. (ed A. L. O. S. Consultant). SINTEF, Staines.

Milinkovitch T, Lucas J, Le Floch S, Thomas-Guyon H, Lefrançois C (2012) Effect of dispersed crude oil exposure upon the aerobic metabolic scope in juvenile golden grey mullet (Liza aurata). Mar Pol Bull 64:865-871

Milinkovitch T, Kanan R, Thomas-Guyon H, Le Floch S (2011) Effects of dispersed oil exposure on bioaccumulation of polycyclic aromatic hydrocarbons and mortality of juvenile Liza ramada. Sci tot environ 409:1643-1650

Petersen LH, Gamperl K (2009). A comprehensive examination of the effects of chronic hypoxia on the cardiorespiratory physiology of Atlantic cod (Gadus morhua). Comparative Biochemistry and Physiology, Part A 153:S56-S63

Ramachandran SD, Hodson PV, Khan CW, Lee K (2004) Oil dispersant increases PAH uptake by fish exposed to crude oil. Ecotox Environ Saf 59:300-308

Randall DJ, Perry SF (1992) Fish Physiology, edition academic press, New York. 
Shiels HA and Farrell AP (1997) The effect of the temperature and adrenaline on the relative importance of the sarcoplasmic reticulum in contributing $\mathrm{Ca}^{2+}$ to force development in isolated ventricular trabeculae from rainbow trout. J Exp Biol 200:1607-1621

Spooner MF (1970) Oil spill in Tarut Bay, Saudi Arabia. Mar Pol Bull 1:166-167.

Thiem A (1994) Degradation of polycyclic aromatic hydrocarbons in the presence of synthetic surfactants. Appli Environ Microbiol 60:258-263

Thomaz JM, Martins ND, Monteiro DA, Rantin FT, Kalinin AL (2009). Cardio-respiratory function and oxidative stress biomarkers in Nile tilapia exposed to the organophosphate insecticide trichlorfon (NEGUVON®). Ecotox Environ Saf 72:1413-1424 